\title{
МОРФОЛОГИЧЕСКОЕ ПЕРЕОПИСАНИЕ ЖИВЕТСКИХ МИОСПОР ЦЕНТРАЛЬНОГО ДЕВОНСКОГО ПОЛЯ
}

\author{
А. А. Щемелинина, М. Г. Раскатова \\ Воронежский государственный университет
}

Поступила в редакцию 3 апреля 2019 г.

\begin{abstract}
Аннотация: в рамках работ по ГДП-200 на территории Центрального девонского поля проведень комплексные биостратиграфические исследования среднедевонских отложений. Появилась возможность расширить и детализировать палинологические исследования живетских отложений исследуемой территории на основе изучения нового кернового материала. В статье приводится морфологическое переописание стратиграфически важных миоспор для расчленения и корреляции живетских отложений (ардатовский, муллинский горизонты) среднего девона. Приведены новые описания и изображения миоспор с учетом их морфологических признаков, и перевод в современную номенклатуру. Полученные результаты исследований позволяют актуализировать таксономию дисперсных миоспор и обеспечивает более обоснованные результаты палиностратиграфических исследований. Полученные палинологические данные могут быть использованы при составлении карт ГДП-200 и серии легенд к ним для Воронежской антеклизы, а также использоваться при корреляичи местных схем с региональными стратиграфическими схемами живетских отложений Восточно-Европейской платформы.
\end{abstract}

Ключевые слова: миоспоры, ардатовский, муллинский горизонты, Центральное девонское поле.

\section{MORPHOLOGICAL REDESCRIPTION OF GIVETIAN MIOSPORE OF THE CENTRAL DEVONIAN FIELDS}

\begin{abstract}
ODP-200, complex biostratigraphic studies of Middle Devonian sediments were conducted in the Central Devonian field. Now it is possible to expand andgjk detail the palynological studies of the givetian deposits of the studied territory based on the study of new core material. The article provides a morphological redescription of stratigraphically important myospores for the dismemberment and correlation of the givetian sediments (Ardatov, Mullin horizons) of the Middle Devonian. New descriptions and images of myospores, taking into account their morphological features, and translation into a modern nomenclature are given. The results of the research allow us to update the taxonomy of dispersed myospores and provide more substantiated results of the pentiratigraphic studies. The obtained palynological data can be used in the mapping of the ODP-200 and a series of legends to them for the Voronezh antecline, as well as used in correlating local patterns with regional stratigraphic patterns of the givetian sediments of the East European Platform.
\end{abstract}

Keywords: miospores, Ardatov, Mullin horizon, Central Devonian fields.

\section{Введение}

В данной работе использовалась морфологическая классификация Р. Потонье и Г. Кремпа [1, 2], с некоторыми дополнениями, внесенными в последующие годы рядом исследователей [3]. Соблюдение строгих правил морфологической классификации явилось основанием для переописания и переименования некоторых видов палеозойских миоспор, ранее выделенных и описанных по классификации С. Н. Наумовой [4] и широко употребляемых для целей стратиграфии. Оформление результатов палинологических исследований проводились в соответствии с общепринятыми рекомендациями $[3,5,6]$.
При описании таксонов видового уровня принята следующая схема: название вида, ссылка на изображение, синонимика, голотип, описание, сравнение, замечание, стратиграфическое распространение, местонахождение и материал [7]. При ревизии спор в оптическом микроскопе анализируются и устанавливаются основные морфологические признаки: полярность, симметрия и экваториальное очертание спор, характер щели разверзания, взаиморасположение слоев экзины и интэкзины, отсутствие или наличие экваториального разрастания экзины и его своеобразие, характер скульптурных элементов экзины, размеры [3]. Новые родовые комбинации предложены для следующих видов (табл. 1). 
Список миоспор живета и их родовая принадлежность в современной номенклатуре

\begin{tabular}{|c|l|}
\hline Предыдущее название вида & \multicolumn{1}{|c|}{ Название вида в новой номенклатуре } \\
\hline Archaeotriletes permagnus Raskatova & $\begin{array}{l}\text { Hystricosporites permagnus (Rask.) Chczemilinina } \\
\text { comb. nov. }\end{array}$ \\
\hline Archaeotriletes perspicuus Raskatova & $\begin{array}{l}\text { Hystricosporites perspicuus (Rask.) M. Raskatova et } \\
\text { Chczemilinina comb. nov. }\end{array}$ \\
\hline Archaeotriletes lemniscatus Raskatova & $\begin{array}{l}\text { Hystricosporites lemniscatus (Rask.) M. Raskatova et } \\
\text { Chczemilinina comb. nov. }\end{array}$ \\
\hline Archaeotriletes capillatus Raskatova & $\begin{array}{l}\text { Hystricosporites capillatus (Rask.) M. Raskatova et } \\
\text { Chczemilinina comb. nov. }\end{array}$ \\
\hline
\end{tabular}

Антетурма Proximegerminates Potonie, 1970

Турма Triletes (Reinsch, 1881) Potonie et Kremp, 1954 Супрасубтурма Acavatitriletes Dettmann, 1963

Субтурма Azonotriletes (Luber, 1935) Dettmann, 1963

Инфратурма Complexati Pashkevich, 1990

Род Hystricosporites McGregor, 1960

Типовой вид. H. delectabili s McGregor - McGregor, 1960.

Dicrospora (pars) - Winslow, 1962, p. 49-52.

Hystricosporites permagnus (Rask.) Chczemilinina comb. nov. Таблица 2, фиг. 1-3

Archaeotriletes permagnus Rask. - Л. Раскатова, 1969, c. 105-106, табл. I, фиг. 4.

Голотип. ВГУ, преп. № 80, Воронежская область, c. Русская Буйловка, скв. 171с, гл. 58,4 м, девон средний, живетский ярус, старооскольский надгоризонт (Л. Раскатова, 1969, с. 105-106).

Описание. Радиальные трехлучевые акаватные азонатные споры, округлого очертания. Щель разверзания простая, лучи щели прямые, длиной в радиус тела споры. Арея слабо различима, на концах лучи щели едва намечают дуги курватуры. Экзина плотная, толстая. Скульптура экзоэкзины на дистальной стороне покрыта плотно расположенными бугорками, на остальной части проксимальной стороны и на дистальной в виде дискретно расположенных длинных выростов $(43,4-59,2 \mu)$ с характерными бифуркирующими окончаниями. Выросты расширены у основания (4-6 $\mu$ ), на концах в виде крючков. Орнаментация за счет скульптурных элементов. Контур спор неровный с выступающими крючкообразными выростами. Цвет спор коричневый.

Размеры: 278,2-305,7 $\mu$.

Сравнение. От Hystricosporites perspicuus (Rask.) M. Raskatova et Chczemilinina comb. nov. и Hystricosporites lemniscatus (Rask.) M. Raskatova et Chczemilinina comb. nov. отличается большими размерами, округлым очертанием, скульптурой экзоэкзины с плотным расположением бугорков, длиной $(43,4-59,2 \mu)$ и характером выростов.

Замечания. Л. Г. Раскатова (1969) описала и отнесла данный вид к подгруппе спор Archaeotriletes c опубликованием в монографии. Однако, следуя современной морфологической классификации дисперсных миоспор, описываемый вид по своим морфологическим признакам соответствует роду Hystricosporites McGreg., 1960, т.к. споры являются акаватными азонатными, с наличием ареи и курватуры, а также наличием скульптуры в виде длинных крючкообразных выростов.

Распространение. Девон средний, живетский ярус, старооскольский надгоризонт ВосточноЕвропейской платформы [8].

Местонахождение. Россия, Воронежская и Курская области, Восточно-Европейская платформа, девон средний, живетский ярус, старооскольский надгоризонт, месторождение «Казинка»: скв. № 3 (инт. 30,2-32,0 м), № 4 (инт. 43,0-47,8 м), № 5 (инт. 41,0-47,0 м), № 16 (инт. 36,2-38,8 м), № 20 (инт. 49,0-56,6 м), № 21 (инт. $38,1-44,0$ м); скв. Воробьевская (инт. 244,0-224,4м); скв. Новохоперская (инт. 262,5-241,7 м); скв. Касторное (инт. 214,9-250,3 м); скв. Кшенский (инт. 175,4-205,4 м).

Материал. 5 экземпляров хорошей сохранности.

Hystricosporites perspicuus (Rask.) M. Raskatova et Chczemilinina comb. nov. Таблица 2, фиг. 4, 5

Archaeotriletes perspicuus Rask. - Л. Раскатова, 1969, с. 105, табл. І, фиг. 3.

Hystricosporites perspicuus (Rask.) M. Rask. in litt. М. Раскатова, 1991, табл. ХІХ, фиг. 3-5.

Голотип. ВГУ, преп. № 402, Воронежская область, с. Мандровка, скв. 777с, гл. 98,6 м, девон средний, живетский ярус, старооскольский надгоризонт (Л. Раскатова, 1969, с. 105).

Описание. Радиальные трехлучевые акаватные азонатные споры, округло-треугольного очертания. Щель разверзания простая, лучи щели прямые, длиной в радиус центрального тела споры. Арея слабо различима, у некоторых экземпляров на концах лучи щели едва намечают дуги курватуры. Экзина плотная, толстая. Структура экзины точечная. Скульптура экзоэкзины на дистальной стороне и в районе экватора рыхло-бугорчатая или в виде мелких плотно прилегающих бугорков, на дистальной стороне дискретно расположены редкие тонкие гладкие выросты длиной 
Палинозона Geminospora extensa морфологическое переописание видов из живетских отложений Центрального девонского поля. Увеличение форм х450.
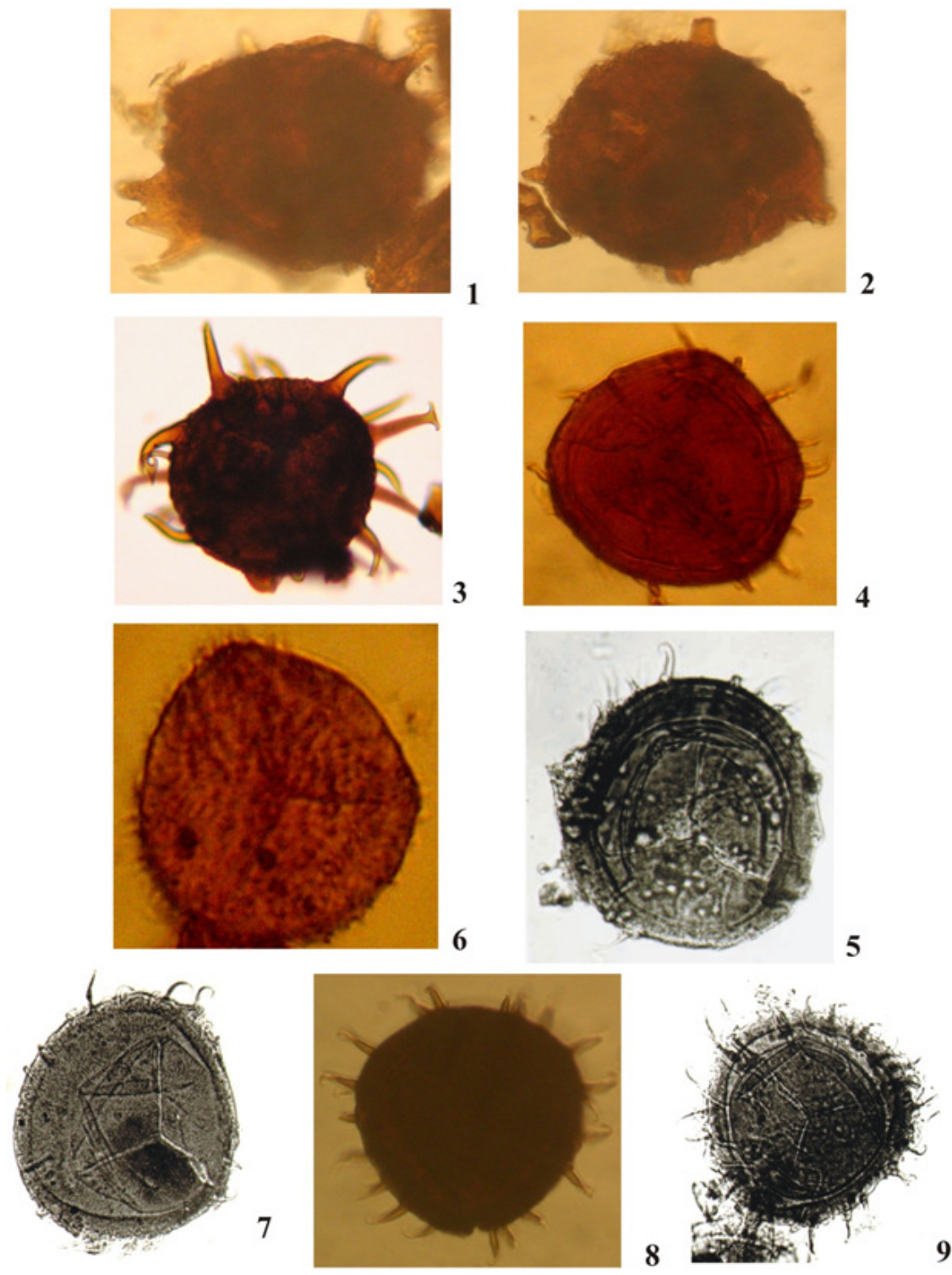

Фиг. 1-3. Hystricosporites permagnus (Rask.) comb. nov. - изображения вида в световом микроскопе: 3, 4 - ВГУ, препарат № 2Вр, Воронежская область, юго-восток окраины с. Воробьевка, скв. Воробьевская, гл. 230,0 м; 7 - ВГУ, препарат 1 Кш/3, Курская область, юго-восток окраины деревни Малая Карповка, скв. Кшенский, гл. 190,4 м, там же.

Фиг. 4, 5. Hystricosporites perspicuus (Rask.) M. Raskatova et Chczemilinina comb. nov. - изображения вида в световом микроскопе: 1- ВГУ, препарат № 1Кс/2, Воронежская область, п. Перлевка, приводораздельная часть левого склона долины p. Серебрянка, скв. Касторное, гл. 222,0 м; 2 - ВГУ, препарат № 4Вр, Воронежская область, юго-восток окраины с. Воробьевка, скв. Воробьевская, гл. 236,0 м, девон средний, живетский ярус, ардатовский горизонт, зона Geminospora extensa (EX), подзона Vallatisporites celeber-Kraeuselisporites violabilis (CV).

Фиг. 6. Hystricosporites lemniscatus (Rask.) M. Raskatova et Chczemilinina comb. nov. - изображение вида в световом микроскопе, ВГУ, препарат № 37/5, Воронежская область, месторождение «Казинка», правобережье р. Казинка, скв. 37, гл. 40,4 м, там же.

Фиг. 7. Hystricosporites lemniscatus (Rask.) M. Raskatova et Chczemilinina comb. nov. - изображение вида в световом микроскопе, Воронежская область, ВГУ, препарат № 1 Кс/9, Воронежская область, п. Перлевка, приводораздельная часть левого склона долины р. Серебрянка, скв. Касторное, гл. 210,0 м, девон средний, живетский ярус, муллинский горизонт, зона Geminospora extensa (EX), подзона Samarisporites triangulatus - Corystisporites serratus (TS).

Фиг. 8, 9. Hystricosporites capillatus (Rask.) M. Raskatova et Chczemilinina comb. nov. - изображения вида в световом микроскопе, ВГУ, препарат № 1Кс/6, Воронежская область, п. Перлевка, приводораздельная часть левого склона долины р. Серебрянка, скв. Касторное, гл. 251,5 м, девон средний, живетский ярус, ардатовский горизонт, зона Geminospora extensa (EX), подзона Vallatisporites celeber-Kraeuselisporites violabilis (CV). 
10,3-26,6 $\mu$, с характерными бифуркирующими окончаниями. Проксимальная сторона тонкая, зернистая. Интэкзина смята в многочисленные складки. Иногда наблюдается смещение центрального тела внутри курватуры. Орнаментация за счет скульптурных элементов. Контур спор неровный с выступающими во все стороны якоревидными, луковицеобразными и крючкообразными выростами. Цвет спор коричневый.

Размеры: 58,6-79,2 $\mu$.

Сравнение. От Hystricosporites permagnus (Rask.) comb. nov. отличается меньшими размерами, округлотреугольным очертанием с редкими тонкими луковицеобразными и крючкообразными выростами

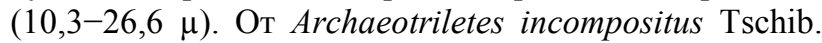
отличается простой щелью разверзания, менее дискретным расположением редких тонких выростов.

Замечания. Л. Г. Раскатова (1969) впервые монографически описала и опубликовала этот вид, и отнесла его по классификации С. Н. Наумовой к подгруппе спор Archaeotriletes. Позднее М. Г. Раскатова (1991) дала комбинацию Hystricosporites perspicuus (Rask.) M. Rask. in litt. с переописанием рода без опубликования. Новый материал хорошей сохранности позволил дополнить и расширить описание данного вида. Следуя современным морфологическим признакам описываемый вид, безусловно, должен быть отнесен к роду Hystricosporites McGreg., 1960, т.к. споры являются акаватными азонатными, с наличием ареи и курватуры, а также обладанием скульптуры в виде длинных якоревидных и крючкообразных выростов.

Распространение. Девон средний, живетский ярус, старооскольский надгоризонт ВосточноЕвропейской платформы [8].

Местонахождение. Россия, Воронежская и Курская области, Восточно-Европейская платформа, девон средний, живетский ярус, старооскольский надгоризонт, месторождение «Казинка»: скв. № 3 (инт. 30,2-32,0 м), № 4 (инт. 43,0-47,8 м), № 5 (инт. 41,0-47,0 м), № 16 (инт. 36,2-38,8 м), № 20 (инт. 49,0-56,6 м), № 21 (инт. $38,1-44,0$ м); скв. Воробьевская (инт. 244,0-224,4м); скв. Новохоперская (инт. 262,5-241,7 м); скв. Касторное (инт. 214,9-250,3 м); скв. Кшенский (инт. 175,4-205,4 м).

Материал. 14 экземпляров хорошей сохранности.

Hystricosporites lemniscatus (Rask.) M. Raskatova et Chczemilinina comb. nov.. Таблица 2, фиг. 6, 7

Archaeotriletes lemniscatus Rask. - Л. Раскатова, 1969, c. 106, табл. II, фиг. 3.

Hystricosporites lemniscatus (Rask.) M.Rask. in litt. - M. Раскатова, 1991, табл. XVIII, фиг. 5-7.

Голотип. ВГУ, преп. № 80, Воронежская область, c. Русская Буйловка, скв. 171с, гл. 58,4 м, девон средний, живетский ярус, старооскольский надгоризонт (Л. Раскатова, 1969, с. 106-107).

Описание. Радиальные трехлучевые акаватные азонатные споры, округло-треугольного очертания. Щель разверзания простая, лучи щели прямые и несколько возвышаются к центру, длиной $2 / 3$ радиуса споры. Арея четко выражена, оконтурена курватурой, иногда наблюдается смещение центрального тела внутри курватуры. Экзина плотная, толстая. Структура экзины точечная. Экзоэкзина на дистальной стороне и в районе экватора - ячеистая (ячейки неправильной овально-удлиненной формы), на проксимальной стороне - зернистая. Скульптура на дистальной стороне и в экваториальной области в виде длинных, прозрачных и тонких выростов (длина $38,6-52,3 \mu$ ) с широким основанием до $2,3 \mu$ а также характерными бифуркирующими окончаниями. Орнаментация за счет скульптурных элементов. Контур спор с выступающими во все стороны крючкообразными и якоревидными выростами. Цвет спор коричневый.

Размеры 82-105,7 $\mu$.

Сравнение. От Hystricosporites perspicuus (Rask.) M. Raskatova et Chczemilinina comb. nov., отличается большим размером и более плотным расположением выростов длиной 38,6-52,3 $\mu$; от H. permagnus (Rask.) comb. nov. - меньшим размером и более редким расположением крючкообразных и якоровидных выростов.

Замечания. Л. Г. Раскатова (1969) описала и отнесла данный вид к подгруппе спор Archaeotriletes. Позднее М. Г. Раскатова (1991) переописывает род без опубликования, как Hystricosporites perspicuus (Rask.) M. Rask. in litt. в ходе изучения нового материала было дополнено и расширено описание данного вида. Следуя современным морфологическим признакам, описываемый вид отнесен к роду Hystricosporites McGreg., 1960, т.к. споры являются акаватными азонатными, с наличием ареи и курватуры, обладают скульптурой в виде длинных якоровидных и крючкообразных выростов.

Распространение. Девон средний, живетский ярус, старооскольский надгоризонт Восточно-Европейской платформы [8].

Местонахождение. Россия, Воронежская и Курская области, Восточно-Европейская платформа, девон средний, живетский ярус, старооскольский надгоризонт, месторождение «Казинка»: скв. № 3 (инт. $30,2-32,0$ м), № 4 (инт. 43,0-47,8 м), № 5 (инт. 41,0-47,0 м), № 16 (инт. 36,2-38,8 м), № 20 (инт. 49,0-56,6 м), № 21 (инт. 38,1-44,0 м); скв. Воробьевская (инт. 244,0-224,4м); скв. Новохоперская (инт. 262,5-241,7 м); скв. Касторное (инт. 214,9-250,3 м); скв. Кшенский (инт. 175,4-205,4 м).

Материал. 16 экземпляров хорошей сохранности.

Hystricosporites capillatus (Rask.) M. Raskatova et Chczemilinina comb. nov.. Таблица 2, фиг. 8, 9 
Archaeotriletes capillatus Rask. - Л. Раскатова, 1969, с. 106, табл. II, фиг. 1, 2.

Hystricosporites capillatus (Rask.) M. Rask. in litt. М. Раскатова, 1991, табл. ХІХ, фиг. 6, 7.

Голотип. ВГУ, преп. № 442, Воронежская область, с. Воронцовка, скв. 260с, гл. 87,5 м, девон средний, живетский ярус, старооскольский надгоризонт (Л. Раскатова, 1969, с. 106).

Описание. Радиальные трехлучевые акаватные азонатные споры, округло-треугольного очертания. Щель разверзания простая, лучи щели прямые, длиной в радиус тела споры. У некоторых экземпляров арея слабо различима, лучи щели едва намечают дуги курватуры. А у других отмечается возвышение ареи к центру схождения лучей с примыкаем к курватурам. Слои экзины расслаиваются в районе экватора и дистальной полусферы. Экзина толстая. Экзоэкзина утолщена на дистальной стороне (до $4 \mu$ ) и утончается на проксимальной (до $2 \mu$ ). Поверхность экзоэкзины на проксимальной стороне зернистая, на дистальной стороне и в районе экватора в виде редко расположенных тонких нитеобразных выростов-шипов (длина 14-28,9 $\mu$ ) с расширением основания до $2 \mu$. Орнаментация за счет скульптурных элементов. Контур спор с выступающими во все стороны длинными выростамишипами. Цвет спор коричневый.

Размеры 80,5-90,5 $\mu$.

Сравнение. От видов рода Hystricosporites (Hystricosporites perspicuus (Rask.) M. Raskatova et Chczemilinina comb. nov., H. permagnus (Rask.) comb. nov., H. lemniscatus (Rask.) M. Raskatova et Chczemilinina comb. nov.) описываемый вид отличается формой скульптурных элементов в виде длинных, тонких, нитеобразных выростов-шипов.

Замечания. Л. Г. Раскатова (1969) опубликовала описание этого вида, и отнесла его по классификации C. Н. Наумовой к подгруппе спор Archaeotriletes. Позднее М. Г. Раскатова (1991) дала комбинацию Hystricosporites perspicuus (Rask.) M. Rask. in litt. c переописанием рода без опубликования. При изучении нового материала, было дополнено и расширено ранее данное описание вида. По своим морфологическим признакам описываемый вид относится к роду Hystricosporites McGreg., 1960, т.к. споры являются акаватными азонатными, с четко выраженной арией, оконтурены курватурой, а также обладают скульптурой в виде длинных выростовшипов.

Распространение. Девон средний, живетский ярус, старооскольский надгоризонт ВосточноЕвропейской платформы [8].

Местонахождение. Россия, Воронежская и Курская области, Восточно-Европейская платформа, девон средний, живетский ярус, старооскольский надгоризонт, месторождение «Казинка»: скв. № 3 (инт. 30,2-32,0 м), № 4 (инт. 43,0-47,8 м), № 5 (инт. 41,0-47,0 м), № 16 (инт. 36,2-38,8 м), № 20 (инт. 49,0-56,6 м), № 21 (инт. 38,1-44,0 м); скв. Воробьевская (инт. 244,0-224,4м); скв. Новохоперская (инт. 262,5-241,7 м); скв. Касторное (инт. 214,9-250,3 м); скв. Кшенский (инт. $175,4-205,4$ м).

Материал. 10 экземпляров хорошей сохранности.

\section{ЛИТЕРАТУРА}

1. Potonie, $R$. Die Gattungen der palaozoischen Sporea dispersae und ihre Stratigraphie/ R. Potonie, G. Kremp// Geol. Jb. -1954 . - Bd. 69. - P. 111-193.

2. Potonie, $R$. Die sporea dispersae des Ruhrkarbons ihre morphographie und stratigraphie mit ausblicken auf Arten anderer Gebiete und Zeitabschnitte / R. Potonie, G. Kremp// Teil I, II, III. Palaeontogr. Abt. B. - 1955. - Bd. 98. - P. 136. 1956: Bd. 99. - P. 85-191. - Bd. 100. - P. 65-121.

3. Ошуркова, М. В. Морфология, классификация и описания форма-родов миоспор позднего палеозоя / М. В. Ошуркова. - СПб.: Изд-во ВСЕГЕИ. - 2003. - 377 с.

4. Наумова, С. Н. Спорово-пыльцевые комплексы верхнего девона Русской платформы и их значение для стратиграфии./ С. Н. Наумова // Девон Русской платформы. - М.: ИГН АН СССР, 1953. - С. 175-253.

5. Avkhimovich, V. I. Middle and Upper Devonian miospore zonation of Eastern Europe / V. I. Avkhimovich [et al.] // Bull. CentresRech. Explor. Prod. Elf Aquitaine. - 1993. - 17(1). - P. 79-147.

6. Методические аспекты палинологии / под ред. И. И.

Нестерова. - М.: Недра, 1987. - 223 с.

7. Барсков, И. С. Палеонтологические описания и номенклатура: учебное пособие / И. С. Барсков, Б. Т. Янин,

Т. В. Кузнецова. - М.: Изд-во МГУ, 2004. - 94 с.

8. Раскатова, Л. Г. Спорово-пыльцевые комплексы среднего и верхнего девона юго-восточной части центрального девонского поля / Л. Г. Раскатова. Воронеж. - 1969. - 167 с.

\section{Voronezh State University}

Chshemelinina A. A., Candidate of Geological and Mineralogical Sciences, manager chief of Geology Museum E-mail: shemelininageol@yandex.ru

Tel.: +7 (473) 2208634

Raskatova M. G., Candidate of Geological and Mineralogical Sciences, associate professor, chair of Historical Geology and Palaeontology Department

E-mail:mgraskatova@yandex.ru

Tel.: +7 (473) 2208634 